\title{
Antibiotics resistance of Stenotrophomonas maltophilia strains isolated from various clinical specimens.
}

\author{
Aytekin Ç1kman ${ }^{1}$, Mehmet Parlak², Yasemin Bayram², Hüseyin Güdücüoğlu², Mustafa Berktaş³
}

1. Mengucek Gazi Education and Research Hospital, Department of Medical Microbiology, Erzincan, Turkey.

2. Yuzuncu Yil University Faculty of Medicine, Department of Medical Microbiology, Van, Turkey.

3. Lokman Hekim Hospital, Microbiology Laboratory, Van, Turkey

\begin{abstract}
Background: A limited number of antibiotics are recommended for the therapy of Stenotrophomonas maltophilia infections due to therapy difficulties caused by its numerous mechanisms of resistance.

Objectives: In this study conducted over a period of approximately 5 years we aimed to determine resistance rates of $S$. maltophilia based on drug classification recommended by Clinical and Laboratory Standards Institute.

Methods: A total of 118 S. maltophilia strains isolated from various clinical specimens between January 2006 and June 2012 were included in the study. BD Phoenixautomated microbiology system (Becton Dickinson, USA) was utilized for species level identification and antibiotic susceptibility testing.

Results: Sixty seven of S. maltophilia strains were isolated from tracheal aspirate isolates, 17 from blood, 10 from sputum, 10 from wound and 14 from other clinical specimens. Levofloxacin was found to be the most effective antibiotic against S. maltophilia strains with resistance rate of $7.6 \%$. The resistance rates to other antibiotics were as follows: chloramphenicol $18.2 \%$, trimethoprim-sulfamethoxazole $20.3 \%$ and ceftazidime $72 \%$.

Conclusion: The study revealed that $S$. maltophilia is resistant to many antibiotics. The treatment of infections caused by $S$. maltophilia should be preferred primarily as levofloxacin, chloramphenicol, and TMP-SXT, respectively.

Keywords: Stenotrophomonas maltophilia, antibiotic, resistance.

DOI: http://dx.doi.org/10.4314/ahs.v16i1.20

Cite as: Çıkman A, Parlak M, Bayram Y, Güdücïoğlu H, Berktas M. Antibiotics resistance of Stenotrophomonas maltophilia strains isolated from various clinical specimens. Afri Health Sci. 2016;16(1): 149-152. http:// dx.doi.org/10.4314/abs.v16i1.20
\end{abstract}

\section{Introduction}

Stenotrophomonas maltophilia is a resistant pathogen that can cause bacteremia, endocarditis, respiratory system, central nervous system and urinary tract infections in patients with risk factors like malignancy or neutropenia, use of broad-spectrum antibiotics like carbapenem or long-term hospitalization ${ }^{1,2}$.

Outside of hospital, S. maltophilia can be found in water resources like rivers, lakes and wells, as well as in soil and various plants. In hospital, these bacteria can be isolated from central venous/arterial monitors, dialysis machines, disinfectant solutions, deionized water, nebulizers, ventilation systems and hands of health care

\section{Corresponding author: \\ Mehmet Parlak, \\ Yuzuncu Yil University Faculty of Medicine, \\ Department of Medical Microbiology, Van, Turkey. \\ Phone: +905052234036 \\ E-mail: mehmetparlak65@hotmail.com}

personnel. Although S. maltophilia can be isolated from wet environments, its long term survival in a dry environment is not very common ${ }^{3,4}$. S. maltophilia possesses virulence factors including DNase, RNase, fibrinolysin, lipases, hyaluronidase, protease, and elastase. These bacteria have the ability to survive in medical soutions and adhere to the prosthetic material ${ }^{5}$.

S. maltophilia can manifest resistance to many commonly used antibiotics, including carbapenems, which makes infections caused by this bacterium difficult to treat ${ }^{6}$. Inappropriate use of broad-spectrum antibiotics like imipenem presents risk factor for $S$. maltophilia infections. The most important reason for this is the ability of S. maltophilia to hydrolyse imipenem? ${ }^{7}$.

S. maltophilia strains are intrinsically resistant to multiple antibiotics due to aminoglycoside acetyl-transferase and enzymes that inactivate erythromycin and genes encoding efflux pumps ${ }^{8}$. Besides the $S$. maltophilia strains being resistant to one antibiotic, these strains can develop resistance to multiple antibiotics (multidrug resistance). 
Due to frequent and irrational use of the broad-spectrum antibiotics, pan resistant strains have been occasionally reported in the hospitals. The aim of this study was to determine resistance rates of $S$. maltophilia strains to the antibiotics specified by CLSI in the context of therapy difficulties caused by its numerous mechanisms of resistance.

\section{Methods}

\section{Study site}

The present study was performed in the microbiology laboratory of Yuzuncu Yil University School of Medicine, Van, Turkey. Our hospital is a 550-bed facility that provides health care to the city of Van and neighboring provinces and thus serves as regional medical center. All together, it provides health care services to the approximately 2.5 million people.

Collection of strains, bacterial identification and antibiotic susceptibility testing

A total of $118 \mathrm{~S}$. maltophilia strains isolated from various clinical specimens between January 2006 and June 2012 were included in the study. In the study, the resistance rates of Stenotrophomonas strains were screened retrospectively. Received samples were inoculated onto 5\% sheep blood agar and EMB agar and incubated for $24 \mathrm{~h}$ at $37^{\circ} \mathrm{C}$. Blood culture samples were analyzed using fully automated blood culture system BacT/Alert 3D (bioMerieux, France). A quantitative sputum culture was performed and specimens yielding $10^{5} \mathrm{CFU}$ per $\mathrm{ml}$ and more were evaluated. BD Phoenix automated microbiology system (Becton Dickinson, USA) was utilized for species level identification and antibiotic suscepti- bility testing of EMB agar lactose and cytochrome oxidase negative, non-fermentative bacteria. The antibiotic classes for $S$. maltophilia strains recommended by CLSI were included in the study ${ }^{10}$. According to the CLSI, MIC interpretive criteria of antibiotic resistance for ceftazidime, trimethoprim-sulfametoxasole, chloramphenicol, and Levofloxacin were accepted as $\geq 32, \geq 4$ PubMed $/ 76, \geq 32$, and $\geq 8(\mu \mathrm{g} / \mathrm{mL})$, respectively.

\section{Study design and statistical analysis}

This study was conducted as a retrospective clinical study. Z test was used for evaluate the difference between antibiotic resistance rate. Level of statistical significance was considered to be $5 \%$ and MINITAB (ver: 14) statistical package program was used for analysis.

\section{Results}

The distribution of 118 S. maltophilia strains according to clinics was as follows: $51 \%$ Pediatrics, 17\% Chest Diseases, 12\% Anesthesia -Intensive Care Unit (ICU), 3\% Otorhinolaryngology, 3\% Internal Medicine, 3\% Neurosurgery and $11 \%$ other clinics. Sixty seven of S. maltophilia strains were isolated from tracheal aspirate isolates, 17 from blood, 10 from sputum, 10 from wound, 3 from ear, 2 from CSF, 2 from paracentesis, 2 from pleural fluid, 2 from urine, 2 from puncture fluid and 1 from catheter. The most effective antibiotic against $S$. maltophilia strains was levofloxacin. The resistance rates of isolated $S$. maltophilia strains to antibiotics recommended by CLSI are shown in Table. Although the difference between trimethoprim-sulfametnoxazole and chloramphenicol has not been found statistically significant, the differences between other antibiotics have been found to be statistically significant $(\mathrm{p}<0.05)$.

Table. The resistance rates of S.maltophilia strains to selected antibiotics (\%)

\begin{tabular}{lcccc}
\hline Antibiotic & Class $^{*}$ & $\mathbf{n}$ & $\mathbf{R}$ & $\begin{array}{c}\text { Resistance } \\
\text { rate (\%) }\end{array}$ \\
\hline Ceftazidime & $\mathrm{B}$ & 118 & 85 & 72 \\
TMP-SXT & $\mathrm{A}$ & 118 & 24 & 20,3 \\
Chloramphenicol & $\mathrm{B}$ & 88 & 16 & 18,2 \\
Levofloxacin & $\mathrm{B}$ & 115 & 9 & 7,6 \\
\hline
\end{tabular}

*: Drug classes specified in CLSI 2010 guidelines (A: routinely reported drugs, B: important drugs and drugs that should be tested with priority) n: Number of tested strains, R: Number of resistant strains,

TMP-SXT: Trimethoprim-sulfametoxasole 


\section{Discussion}

In recent years non fermentative Gram negative bacteria (Pseudomonas aeruginosa, Acinetobacter baumannii, Stenotrophomonas maltophilia ve Burkholderia cepacia) have been increasingly recognized as an important cause of nosocomial infections. Many difficulties are encountered in the treatment of these infections due to multiple antibiotic resistance of these bacteria ${ }^{10,11}$. S. maltophilia related nosocomial infections occur more frequently in immunocompromised patients and patients on mechanic ventilation in ICU and these infections are usually associated with high morbidity and mortality rates ${ }^{12}$. Natural resistance of $S$. maltophilia to multiple antibiotics used against Gram-negative bacteria increases mortality rates in all $S$. maltophilia infections, especially in bacteremia. Araoka et $\mathrm{al}^{13}$ reported mortality rate higher than $50 \%$ in the patients with $S$. maltophilia related bacteremia.

In the previous studies $S$. maltophilia has been isolated mainly from respiratory $(49 \%)$ and blood samples (41\%). In our country, similarly, the most common clinical material for isolation of $S$. maltophilia consists of respiratory and blood samples. Celebi et $\mathrm{al}^{14}$ reported that this bacterium was mainly isolated from respiratory $(67 \%)$ and blood $(16 \%)$ samples. In accordance with literature, respiratory $(65 \%)$ and blood (14\%) samples were the most common clinical material for the isolation of $S$. maltophilia in the present study as well.

S. maltophilia strains isolated from the sample according to the diagnostic criteria were admitted to the respiratory pathogen.

Limited therapy options are available for the treatment of infections associated with $S$. maltophilia strains due to their natural resistance to many antibiotics like beta-lactam antibiotics or aminoglycosides ${ }^{15}$. According to in vitro studies, the most effective antibiotics for $S$. maltophilia strains are levofloxacin and TMP-SXT. In a study of Hankiewicz et $\mathrm{al}^{16}$ conducted with 80 clinical isolates of $S$. maltophilia strains of which $60 \%$ were multiple resistant, resistance rates for levofloxacin and TMP-SXT were found to be $4 \%$ and $29 \%$, respectively . Sader et $\mathrm{al}^{17}$ reported resistance to levofloxacin as $7 \%$ and resistance to SXT as 5\%. In our country, Turk Dagi et $\mathrm{al}^{18}$ worked with $S$. maltophilia strains isolated from blood culture and determined resistance rates of levofloxacin and TMP-SXT as 20\% and 10\%, respectively. On the other hand, Dizbay et $\mathrm{al}^{19}$ reported resistance to TMP-SXT as $22 \%$ in a sample of 89 nosocomial
S.maltophilia strains. In the present study resistance rate to levofloxacin and TMP-SXT were $7.6 \%$ and $20.3 \%$ respectively, which is in accordance with previous studies. Some researchers have argued that despite low resistance rate of TMP-SXT it should be used in combination with some other antimicrobial agent due to its low efficacy when used alone ${ }^{16}$.

Chloramphenicol has been reported by several studies as a highly efficient antibiotic against $S$. maltophilia strains. In a study of Niks et $\mathrm{al}^{20}$, chloramphenicol resistance was $23 \%$ in multiresistant hospital bacterial pathogens. Nicodemo et $\mathrm{al}^{21}$ compared three different methods and reported chloramphenicol resistance between 19 and 23\%. Although data on chloramphenicol resistance in our country was insufficient, in the present study resistance rate to chloramphenicol was found to be $18 \%$. Despite its low resistance rate chloramphenicol is not widely used in clinical practice due to its potential side effects like bone marrow suppression or plastic anemia $^{22}$.

Resistance of $S$. maltophilia strains to ceftazidime vary. In a study from Europe of Masgala et $\mathrm{al}^{23}$ ceftazidime resistance was reported as $24 \%$. On the other hand, resistance rates to ceftazidime reported in our country are considerable higher. In the studies conducted in Turkey, Dizbay et $\mathrm{al}^{19}$ found ceftazidime resistance rate to be $45 \%$, TurkDagi et $\mathrm{al}^{18} 78 \%$ and Zer et $\mathrm{a}^{16} 88 \%$. Results regarding ceftazidime resistance rate obtained in this study $(72 \%)$ are in accordance with national data.

Carbapenems are widely used antibiotics for empirical treatment of infections with Gram negative bacteria in hospital and especially in intensive care units. This causes treatment delay and leads to the rise of infections related to opportunistic pathogens like $S$. maltophilia which is naturally resistant to carbapenems. For this reason, pathogens resistant to multiple commonly used antibiotics, with high transmissibility in ICU and with problematic diagnosis and treatment like $S$. maltophilia should be considered as cause of infection in long-stay patients, patients with malignancy or neutropenia and patients using broad-spectrum antibiotics like carbapenem.

\section{Limitation}

Firstly, the study was conducted retrospectively. Secondly, study was carried out in one center only. Multicenter study should be done with more strains. 


\section{Conclusion}

The study revealed that $S$. maltophilia is resistant to many antibiotics. The treatment of infections caused by $S$. maltophilia should be preferred primarily as levofloxacin,chloramphenicol,and TMP-SXT, respectively. Additionally, treatment planning in accordance with in vitro susceptibility test results are required for efficient treatment of S.maltophilia infections.

\section{Conflict of interest}

None

\section{References}

1. Yıldırım F, Yaşar KK, Şengöz G, Yamanlar R, Nayman F, İdin K. Erişkin yoğun bakım ünitesinde Stenotrophomonas maltophilia infeksiyonu ve kontrolü. ANKEM Derg 2009; 23(4): 166 -71.

2. Köseoğlu O, Sener B, Gür D. Molecular epidemiology of Stenotrophomonas maltophilia strains isolated from paediatric patients. Mikrobiyol Bul 2004; 38: 9-19.(1-2 PubMed )

3. Brooke JS. Stenotrophomonas maltophilia: an emerging global opportunistic pathogen. Clin Microbiol Rev 2012;25(1): 2 -41.

4. Denton M, Kerr KG. Microbiological and clinical aspects of infection associated with Stenotrophomonas maltophilia. Clin Microbiol Rev 1998; 11(1): 57-80. PubMed 5. Enoch DA, Birkett CI, Ludlam HA. Non-fermentative Gram-negative bacteria. Int J Antimicrob Agents 2007; 29(3): 33-41.

6. Zer Y, Karaoğlan I, Çevik S, Erdem M. Stenotrophomonas maltophilia suşlarının antibiyotik duyarlılıklarının irdelenmesi. Klimik Derg 2009; 22(1): 21 -4.

7. Krcmery V Jr, Sykora P, Trupl J et al. Antibiotic use and development of resistance in blood culture isolates: 8 years of experience from a cancer referral center. $J$ Chemother 2001; 13(2): 133 -42.

8. Valdezate S, Vindel A, Loza E, Baquero F, Cantón R. Antimicrobial susceptibilities of unique Stenotrophomonas maltophilia clinical strains. Antimicrob Agents Chemother 2001; 45(5): 1581-4.

9. Öztürk R. Çoklu ilaç dirençli Pseudomonas aeruginosa, Burkholderia cepacia, Stenotrophomonasmaltophilia ile oluşan infeksiyon hastalıklarında antimikrobik tedavi. ANKEM Derg 2008; 22(Ek 2): 36-43.

10. Clinical and Laboratory Standards Institute (CLSI). Performance standards for antimicrobial susceptibility testing; Twentieth informational supplement, M100-S20, CLSI, Wayne PA (2010).

11. Hancock RE. Resistance mechanisms in Pseudomonas aeruginosa and other nonfermentative Gram-negative bacteria. Clin Infect Dis 1998; $27(1)$ : 93 -9.

12. Nyc O, Matejková J. Stenotrophomonas maltophilia: Significant contemporary hospital pathogen - review. Folia Microbiol (Praha) 2010; 55(3): 286 -94.

13. Araoka H, Baba M, Yoneyama A. Risk factors for mortality among patients with Stenotrophomonas maltophilia bacteremia in Tokyo, Japan, 1996-2009. Eur J Clin Microbiol Infect Dis 2010; 29(5): 605-8.

14. Çelebi S, Kavurt S, Hacımustafaoğlu M. Çocuklarda hastaneden edinilmiş Stenotrophomonas maltophiliainfeksiyonlar: Beş yıllık çalışma sonuçları. Çocuk Enf Derg 2008; (2)3: 100 -4.

15. Azap ÖK, Timurkaynak F, Arslan H, Karaman SÖ. Hastane infeksiyon etkeni olarak izole edilen non-fermentatif Gram negatif bakterilerde siprofloksasin, ofloksasin ve levofloksasinin in-vitro etkinliğinin karşılaştırılması. Ankara Üniv Tip Fak Mecm 2004; 57(4): 189 -94.

16. Hankiewicz-Ziołkowska K, Mikucka A, Gospodarek E. Clinical strains isolation and antibiotic susceptibility of Stenotrophomonas maltophilia. Med Dosw Mikrobiol 2010; 62(2): 127 -34.

17. Sader HS, Jones RN. Antimicrobial susceptibility of uncommonly isolated non-enteric Gram-negative bacilli. Int J Antimicrob Agents 2005; 25(2):95-109.

18. Türk Dağ1 H, Arslan U, Tuncer İ. Kan kültürlerinden izole edilen Stenotrophomonas maltophilia suşlarının antibiyotik direnci. ANKEM Derg 2011; 25(1): 27 -30.

19. Dizbay M, Tunccan OG, Sezer BE, Aktas F, Arman D. Nosocomial Burkholderia cepacia infections in a Turkish university hospital: a five-year surveillance. J Infect Dev Ctries 2009; 3(4): 273-7.

20. Niks M, Hanzen J, Ohlasová D. Multiresistant nosocomial bacterial strains and their "in vitro" susceptibility to chloramphenicol and colistin. Klin Mikrobiol Infeke Lek 2004; 10(3): 124-9.

21. Nicodemo AC, Araujo MR, Ruiz AS, Gales AC. In vitro susceptibility of Stenotrophomonas maltophilia isolates: comparison of disc diffusion, Etest and agar dilution methods. J Antimicrob Chemother 2004; 53(4): 604-8.

22. Falagas ME, Grammatikos AP, Michalopoulos A. Potential of old-generation antibiotics to address current need for new antibiotics. Expert Rev Anti Infect Ther 2008; 6(5): 593-600.

23. Masgala A, Galani I, Souli M, Giamarellou H. Discrepancies between various methods in susceptibility testing and epidemiological analysis of Stenotrophomonas maltophilia clinical isolates. Cent Eur J Public Health 2010; 18(2): 119-23. 